\title{
A criação de municípios no front e a formação da elite do agronegócio: faces do uso do território brasileiro*
}

Silvana Cristina da Silva ${ }^{* *}$

\section{Resumo}

Este artigo objetiva mostrar como o processo de criação de novos municípios no front agrícola do território brasileiro, em especial no estado do Mato Grosso, conecta-se ao uso dado a esse subespaço do território. Além disso, este artigo destaca que a dinâmica de criação de fronteiras internas municipais no front está associada à formação de uma nova elite, a elite do agronegócio. Essa elite comanda a parcela técnica do circuito espacial de produção e parte do círculo de cooperação da produção de commodities, utilizando o Estado, em suas diferentes escalas, para manter-se como elite e promover a atividade econômica que domina a região. Isso resulta na existência de uma conformação do uso corporativo do território que, além de atender aos interesses da elite do agronegócio, também atende aos interesses das grandes corporações.

Palavras-chaves: Criação de município; Front; Agronegócio; Elite; Uso do território.

* Esse artigo é resultado de pesquisa financiada pela Fundação de Amparo à Pesquisa de São Paulo (FAPESP).

** Doutoranda do Programa de Pós Graduação em Geografia do Instituto de Geociências - UNICAMP (silvana.silva@ige.unicamp.br).

Geosul, Florianópolis, v. 24, n. 48, p 85-101, jul./dez. 2009 
SILVA, S.C. da. A criação de municípios no front e a formação da elite ...

The municipality creation in the front and the formation of the agribusiness elite: the faces of the brazilian territory use

\begin{abstract}
The purpose of this article is to show how the process of creation of new municipalities in the agricultural front of the Brazilian territory, in particular in the State of Mato Grosso, relates to the use given to this territory subspace. In addition, this article highlights that the dynamics of creation of municipal internal frontiers in the front is associated with the formation of a new elite, the agribusiness elite. These elite command the technical part of the space production circuit and part of the cooperation circle of production of commodities, using the State, at its different scales, to maintain themselves as elite and to promote the economic activity that dominates the region. This results in the existence of a conformation of the corporate use of the territory which, in addition to meeting the interests of the agribusiness elite, also meets the interests of major corporations.
\end{abstract}

Key words: Municipality creation; Front; Agribusiness; Elite; Use of territory.

\title{
Introdução
}

O território brasileiro, embora se insira como uma formação sócio-espacial (SANTOS, 1977) ancorada ao sistema capitalista mundial, apresenta dinâmicas regionais diferenciadas. Algumas regiões brasileiras mudaram a estrutura produtiva, populacional, a divisão político-administrativa e criaram novas classes dominantes. Isso ocorreu em função dos novos usos impostos a essas regiões.

O espaço, ao longo da história, revelou as formas diferenciadas dos modos de produção. Os sucessivos modos de produção organizaram o espaço de maneiras distintas, assumindo as particularidades de cada lugar (MORAES \& COSTA, 1987). O modo de produção capitalista que se implantou no Centro-oeste brasileiro tomou formas específicas nessa região. O uso agrícola do 
SILVA, S.C. da. A criação de municípios no front e a formação da elite ...

Centro-oeste impôs um ritmo acelerado de modernizações. Essas não foram apenas modernizações técnicas, mas também no modo de organização do espaço. As novas unidades políticoadministrativas municipais e a novas classes dominantes expressam parte da profundidade das transformações desse subespaço do território.

O Centro-oeste brasileiro caracteriza-se pela funcionalidade produtiva em commodities. A soja é o produto que se destacou, no entanto, outros como o milho, o algodão e a cana, cada vez mais se tornam significativos no sistema produtivo desta região. A modernização agrícola atingiu parte do Centro-oeste, onde se convencionou chamar de front agrícola. Essa região engloba os estados do Mato Grosso, Tocantins, Goiás, Sul do Pará, Oeste da Bahia, Maranhão e Rondônia. Destacamos que a modernização do front não é homogênea.

O front é um exímio exemplo de transformação espacial, pois, recebeu o meio técnico-científico-informacional (Santos, 2002) de maneira acelerada A ocupação do front por atividades agrícolas modernas caracterizou-se pela forte migração, principalmente de pessoas da região Sul do país, pela forte urbanização e municipalização (criação de municípios). Ou seja, houve nesta região modificação da estrutura populacional, surgimento de cidades novas e crescimento do número de municípios, em função da necessidade de autonomia dos novos centros urbanos.

A modernização agrícola do front, em especial do Mato Grosso, revela que a criação de novos municípios relaciona-se com o processo de formação das novas elites regionais brasileiras, que por sua vez conecta-se ao uso atribuído a esse subespaço do território nacional.

Objetivando elucidar esses processos apresenta-se neste artigo uma discussão da dinâmica de criação de novos municípios no estado de Mato Grosso, explicitando a geração da família de municípios do agronegócio. Discute-se também a relação entre o uso agrícola do território e a formação das novas elites regionais, 
SILVA, S.C. da. A criação de municípios no front e a formação da elite ...

denominada elite do agronegócio. Além disso, dialoga-se sobre os efeitos deletérios desse uso do território, visível pela segregação territorial observada na paisagem da família de municípios do agronegócio.

\section{A geração da família de municípios do agronegócio}

A modernização agrícola no estado do Mato Grosso tem na urbanização sua complementaridade. Muitas cidades nasceram para atender demandas do agronegócio. Esses novos centros urbanos que surgiram reclamam autonomia política, concretizada em parte na forma da emancipação municipal.

No Brasil o município é um ente federativo que produz leis e possui recursos (conquanto limitados) que permitem certa autonomia política à cidade. Dessa maneira, o município tornou-se um importante elemento de análise da urbanização brasileira, sobretudo, em regiões de moderna agricultura. Por isso ampliamos o conceito de "família de cidades"1 para família de municípios.

A urbanização no front agrícola foi condicionada à criação de novos municípios para completar-se; estes, por sua vez, trazem as normas e políticas públicas locais que auxiliam o desenvolvimento da economia agrícola. Neste contexto, o conceito "família de municípios do agronegócio" denota o conjunto dos municípios criados em função da produção de commodities agrícolas, sobretudo a soja.

A família de municípios do agronegócio caracteriza por ser um conjunto de municípios novos ou municípios antigos com novas infra-estruturas, que surgem como resposta às solicitações do mercado para uma produção moderna, tendo em comum uma única dinâmica econômica a lhes imprimir seu movimento. São municípios que se inserem como órgãos "derivados" no organismo

\footnotetext{
${ }^{1}$ Muitos geógrafos trabalham com o conceito de família de cidades, como por exemplo, Deffontaines (1944), Geiger (1963), Brunhes (1962), Santos $(1965,1994)$ e Silveira (1999), para identificação dos períodos relevantes na constituição de cada formação sócio-espacial.
} 
SILVA, S.C. da. A criação de municípios no front e a formação da elite ...

regional, reorganizando a antiga ordem do conjunto para impor novos usos regionais não mais somente a partir de uma ordem local, mas, sobretudo, a partir de uma ordem global (SILVA \& CATAIA, 2005; SILVA, 2007).

A Tabela 01 abaixo mostra os principais municípios produtores de soja no estado do Mato Grosso, bem como seus respectivos anos de criação.

Tabela 01: Ano de criação e origem dos maiores produtores de soja do Mato Grosso - 2006

\begin{tabular}{|l|l|c|l|c|}
\hline \multicolumn{2}{|c|}{ Municipio } & $\begin{array}{c}\text { Ano de } \\
\text { Criação }\end{array}$ & Município de Origem & $\begin{array}{c}\text { Produção de } \\
\text { Soja (ton.) }\end{array}$ \\
\hline 1 & Sorriso & 1986 & Nobres & 1.789 .974 \\
\hline 2 & Nova Mutum & 1989 & Diamantino & 962.045 \\
\hline 3 & Sapezal & 1994 & Campo Novo dos Parecis & 931.653 \\
\hline 4 & Campo Novo dos Parecis & 1989 & Diamantino & 868.770 \\
\hline 5 & Diamantino & 1820 & Cuiabá & 794.880 \\
\hline 6 & Lucas do Rio Verde & 1989 & Diamantino & 684.032 \\
\hline 7 & Nova Ubiratã & 1995 & Vera e Sorriso & 631.029 \\
\hline 8 & Campos de Júlio & 1997 & Várzea Grande & 591.963 \\
\hline 9 & Primavera do Leste & 1987 & Poxoréo & 550.440 \\
\hline 10 & Querência & 1991 & $\begin{array}{l}\text { Canarana e São Félix do } \\
\text { Araguaia }\end{array}$ & 461.100 \\
& & & \multicolumn{2}{|}{} \\
\hline
\end{tabular}

Fonte: Elaboração da autora.

Por meio da análise da origem dos maiores municípios produtores de soja (Tabela 01), constatamos que a maior parte desses municípios surgiram recentemente e desmembraram-se de antigos municípios da mineração (séculos XVII e XVIII) como Cuiabá, Diamantino e Poxoréo, ou seja, essas emancipações muitas vezes ocorrem numa tentativa dos municípios mais "dinâmicos" se desligarem da antiga sede municipal, considerada obsoleta e lenta para a nova atividade.

Já o Mapa 01 a seguir mostra a produção de soja no estado do Mato Grosso, localizando os dez maiores produtores: 
SILVA, S.C. da. A criação de municípios no front e a formação da elite ...

Mapa 01: Quantidade produzida de soja (ton.) por municípios e localização dos 10 maiores produtores - Mato Grosso/2006

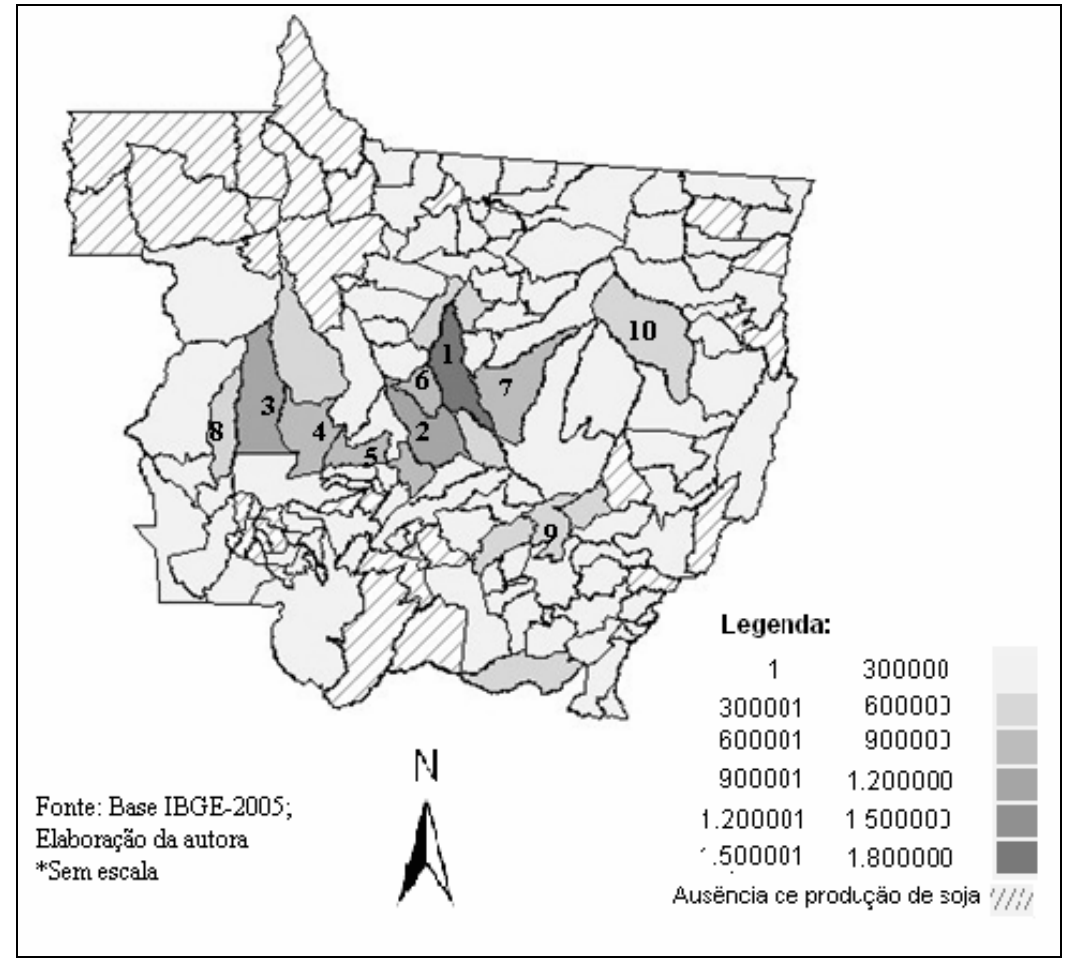

Pode-se verificar, portanto, que os maiores produtores de soja fazem parte da família de municípios do agronegócio, pois reúnem as características comuns: foram criados recentemente (exceção de Diamantino), têm elevada produção e possuem em seus territórios forte especialização produtiva com o intuito de atender as demandas do agronegócio. Os maiores produtores de soja exemplificam, assim, a conformação da especialização produtiva na região Centro-oeste, em especial no estado de Mato Grosso. 
SILVA, S.C. da. A criação de municípios no front e a formação da elite ...

Em função do aumento do número de municípios criados após a Constituição de 1988, foi editada a emenda constitucional número 15 de 1996 que estabelece novas regras para a emancipação municipal. Devido à ambigüidade do texto, principalmente sobre a esfera que deveria legislar sobre o assunto (estadual ou federal), esta emenda acabou sendo proibitiva às emancipações municipais pela falta de regulamentação. Até o presente momento a emenda constitucional não foi regulamentada e teoricamente deveriam estar suspensas novas emancipações municipais, o que na prática só passou a ocorrer após 2001.

Apesar dessa Emenda Constitucional, as propostas de emancipações municipais continuam sendo encaminhadas aos legislativos estaduais. Hoje existem 54 propostas de criação de novos municípios tramitando na Assembléia Legislativa do estado do Mato Grosso. Analisou-se 27 dessas propostas ${ }^{2}$, são elas: Alto Coité, Analândia do Norte, Boa Esperança do Norte, Campina Verde (Campina do Araguaia), Cardoso d'Oeste (Vale do Aguapeí), Colorado do Norte, Culuene, Espigão do Leste, Estrela do Araguaia, Itaquerê, Mario Covas, Nova Floresta, Nova Primavera, Nova Terra Roxa, Nova União, Ouro Branco do Sul, Paranorte, Paredão Grande (Paredão do Leste), Pedra Neca, Pontinópolis, Rio Xingu ("Coutinho União"), Salto da Alegria, Santo Antônio do Fontoura, São José do Apuí, São José do Couto, Serra Verde e União do Norte.

Destacamos que grande parte dos pedidos por emancipações está próximo aos eixos de circulação e nos novos fronts do estado, como por exemplo, na BR-158, novo eixo de expansão da produção de soja no estado. O Mapa 02 localiza estas propostas.

\footnotetext{
${ }^{2}$ Não foi possível a análise das outras 27 propostas em função da não disponibilização das informações pela Assembléia Legislativa do estado do Mato Grosso.
} 
SILVA, S.C. da. A criação de municípios no front e a formação da elite ...

Mapa 02: Localização das propostas de criação de novos municípios em MT /2007

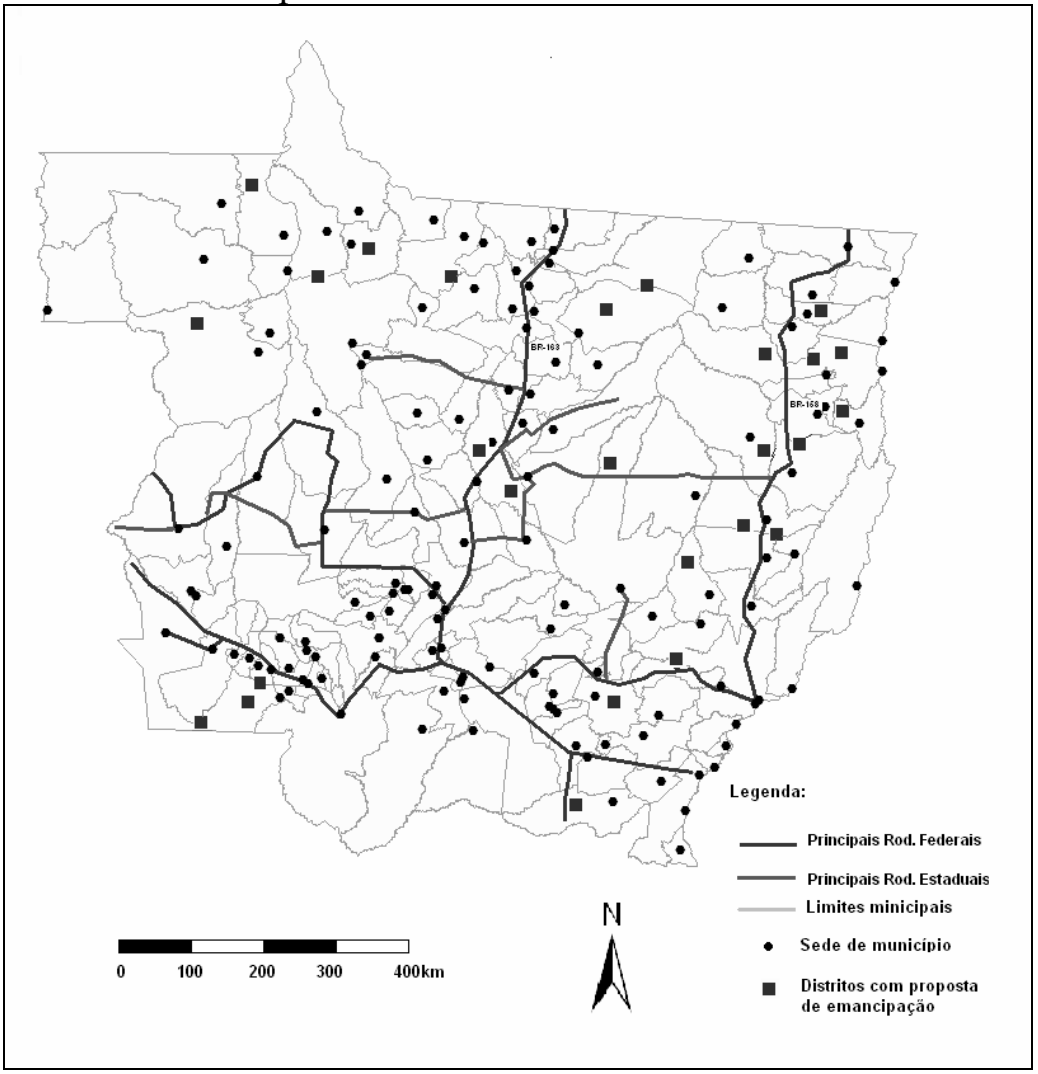

Fonte: Base IBGE, 2005; Elaboração Silvana Cristina da Silva \& Daniel Cândido.

\section{O uso do território e a formação da elite do agronegócio}

Os novos municípios do estado do Mato Grosso têm na estrutura da sociedade local um importante elemento explicativo do funcionamento da modernização agrícola.

A maioria desses municípios é formada por migrantes vindos de quase todo Brasil, sobretudo dos estados da região Sul. 
SILVA, S.C. da. A criação de municípios no front e a formação da elite ...

Por isso são chamados genericamente no Centro-oeste de "sulistas". Os sulistas são os responsáveis pela criação de muitas cidades e também pelo comando das mesmas. Na maioria dos novos municípios os cargos políticos da cidade são ocupados pelos migrantes do Sul.

Segundo Raffestin (1993), a população constitui-se em um dos trunfos do poder. A formação e a distribuição da população residem no fato de ela ser concebida como um recurso. É fato histórico que o Estado tem todo interesse numa distribuição estratégica da população pelo território. Entretanto, hoje são as empresas as maiores responsáveis pelo deslocamento e concentração da população em determinados lugares. As empresas procuram realizar a maior mobilidade geográfica possível da população para satisfazer suas necessidades de mão-de-obra.

A mobilidade da população provinda do Sul ocorreu primeiramente por meio de políticas territoriais estatais que, além de atender objetivos estratégicos, atendiam também as exigências do mercado. Neste caso, não se pode afirmar que a decisão de migrar seja uma decisão individual, mas é conseqüência de um processo mais amplo que envolve os novos usos do território. Uma nova divisão territorial do trabalho, valorizando novas áreas e, por conseqüência, desvalorizando relativamente outras, põe em marcha migrações, produzindo novas divisões sociais e territoriais do trabalho.

A opção pelos sulistas não foi aleatória, na verdade eles viriam a ser o grupo social ideal para a concretização do projeto de produção de commodities, pois era necessário que no processo de incorporação de novas áreas, se mantivesse o sentido de produzir para o mercado externo e a concentração da propriedade privada nas antigas áreas de ocupação e nas novas áreas (ALVES, 2005).

Segundo Alves (2005), à medida que o capital elege uma área para a produção ele também elege o grupo social que alavancará a produção. Assim ocorreu a ocupação pelos sulistas no estado do Mato Grosso e no front agrícola de modo geral. 
SILVA, S.C. da. A criação de municípios no front e a formação da elite ...

A transferência da população sulista para o Mato Grosso, embora fosse movida pelas atividades agrícolas, impulsionou a urbanização, sobretudo porque o circuito espacial e o circulo de cooperação (SANTOS \& SILVIRA, 2001) da produção de soja é dado pelos elementos do sistema urbano, como concentração de distribuidores de insumos, maquinários, rede bancária e também pela presença do poder político local (para atender os meios de consumo coletivo da mão-de-obra e a regulação do município).

Os sulistas comandam o processo de modernização agrícola no front compondo a elite do poder nessa região. Segundo Mills (1981), a elite do poder é composta por indivíduos cuja posição lhes permite transcender o ambiente comum dos indivíduos comuns, e tomar decisões de grandes conseqüências, pois comandam as principais hierarquias e organizações da sociedade moderna (como a "máquina do Estado"), ocupando os postos estratégicos que lhes permitem aumentar sua riqueza e manter-se no poder. $\mathrm{O}$ autor ainda acrescenta que na sociedade moderna, os domínios das esferas econômicas, políticas e militares é que confere poder aos indivíduos. Por isso a elite compõe-se de grandes executivos e diretores de grandes empresas, de chefes políticos e de militares do alto escalão, ainda que a elite não seja somente composta por eles.

Para Mills (1981), os poderosos são aqueles capazes de realizar suas vontades mesmo com resistências. Para isso é necessário o acesso às instituições e, ainda que o poder não emane apenas pelo acesso às instituições, é somente através delas que o poder torna-se permanente e contínuo. A sociedade local estruturase em grupos, cujos membros decidem assuntos importantes da comunidade. Esses grupos não se organizam com formalidades e centralizam suas decisões na esfera econômica.

Mills (1981) assevera que as elites são formadas hierarquicamente. Assim ele lembra que abaixo da alta cúpula das decisões locais há um segundo grupo, que influencia aqueles que podem tomar a decisão de fato. São os vice-presidentes de bancos, pequenos homens de negócio, funcionários públicos de alta 
SILVA, S.C. da. A criação de municípios no front e a formação da elite ...

categoria, empreiteiros e os executivos das indústrias locais. Um terceiro grupo compor-se-ia dos chefes das instituições cívicas, funcionários, pequenos líderes cívicos e jornalistas. Um quarto grupo seria formado pelos profissionais de negócios, sacerdotes, professores universitários, assistentes sociais e diretores de pessoal.

Para Castro (1992), trabalhar com o conceito de elite significa trabalhar empiricamente com diferenças sociais, ou seja, com níveis hierárquicos de poder na sociedade. "Como relações sociais assimétricas são conformadas pela distribuição desigual do poder econômico e de poder político, o conceito de elite, contém, implicitamente, uma qualificação de poder, no qual o político e o econômico interagem e se reforçam" (CASTRO, 1992, p. 28).

$\mathrm{Na}$ análise da dinâmica territorial matogrossense, observa-se a formação de um grupo político poderoso. $\mathrm{O}$ atual governador do estado do Mato Grosso é Blairo Maggi, líder do maior grupo de origem nacional da produção e logística da soja, o Grupo Amaggi.

A elite política local e regional do estado do Mato Grosso, composta em sua maioria por sulistas, comanda o front agrícola. Esses agentes já vêm do sul do Brasil com um poder aquisitivo superior à população matogrossense. Assim, ressaltamos que não se trata apenas de uma condição cultural diferenciada, mas, sobretudo de uma questão de classe social. A questão cultural existe de fato, mas a segregação existente nos novos municípios é antes de tudo uma questão de desigualdades sócio-territoriais que, como em qualquer região brasileira, é uma das bases do funcionamento do capital.

Pode-se nomear a elite dos municípios de moderna agricultura do front agrícola como a elite do agronegócio, pois esta comanda a parcela técnica do circuito produtivo e do circulo e cooperação da produção de commodities, sobretudo da soja, e utiliza-se do Estado em suas diferentes escalas para manter-se como elite política e promover a atividade econômica que domina a região. 
SILVA, S.C. da. A criação de municípios no front e a formação da elite ...

Dessa forma, constata-se que o uso agrícola do território condicionou a formação de grupos dominantes, e, ao mesmo tempo, esses grupos dominantes utilizaram e utilizam mecanismos que acabam por promover esse uso do território. A redivisão político-administrativa é um desses mecanismos.

Castro (1992), analisando a composição da elite do Nordeste brasileiro (entre 1946-1987) em uma tentativa de explicar o regionalismo criado nesta região que alimenta a pobreza e a famigerada "indústria da seca", aponta que, em média, 95\% dessa elite compõem-se de empresários e profissionais liberais, tendo a classe trabalhadora insignificância nas representações. Resguardando as especificidades regionais e locais, verifica-se que essa estrutura da composição da elite política se repete na maior parte dos municípios da família de municípios do agronegócio.

Isso pode ser exemplificado através da análise do município de Sorriso-MT, o maior produtor de soja do Brasil, onde se verifica uma dificuldade de acesso das classes menos favorecidas ao poder político dessa cidade. O que acarreta um aprofundamento das desigualdades e da segregação, uma vez que os grupos denominados elite em Sorriso compõem-se pelos empresários do comércio, serviços e produtores rurais, quase todos esses envolvidos no circuito de produção da soja e em seu circulo de cooperação. Estes, por meio do acesso à decisão (Estado), possuem o poder de orientar as "políticas públicas" locais, realizadas pelo município e também as políticas regionais efetuadas pelos governos estaduais e mesmo pela União.

A prefeitura de Sorriso é comandada por Dilceu Rossato, grande produtor de soja no município e de origem sulista. As principais lideranças locais do município originam-se das famílias dos "pioneiros" do sul. Entre as famílias mais influentes estão as famílias Frâncio, Dalmolin, Daroit e Schewinski (todas as quatro pioneiras) ${ }^{3}$.

${ }^{3}$ Haesbaert (1998) afirma que também há muitas prefeituras comandadas por sulistas no Sul do Amazonas, nas manchas de modernização na Bahia e Piauí. 
SILVA, S.C. da. A criação de municípios no front e a formação da elite ...

A criação de novas municipalidades é uma maneira da elite do agronegócio fazer valer seus interesses, que são divergentes das populações pré-existentes ou provindas de outros lugares do território. $\mathrm{O}$ acesso político à prefeitura dá acesso aos recursos públicos, que passam a ser utilizados segundo interesses dessa elite do agronegócio. Dessa forma, elite econômica e política confundem-se.

Kahil (2005) aponta como no Brasil permanece a oscilação entre os interesses clientelistas do mandonismo local e os interesses de setores privados específicos que articulam a política econômica supranacional. Esse "par perfeito" acaba produzindo um novo rearranjo territorial, como ocorreu na região Centro-oeste, tornando esta região obediente às demandas do mercado internacional e, ao mesmo tempo, aos interesses da elite política local. A criação de novos municípios no Mato Grosso vem revelando $o$ funcionamento perfeito entre a racionalidade econômica (representada pela produção de commodities, comandada pelo mercado) que necessita da base técnica e normativa para sua expansão e os interesses políticos e econômicos da elite local.

As novas municipalidades do Mato Grosso são controladas por alguns agentes, que usam o espaço privasticamente, caracterizando um uso corporativo desse subespaço do território brasileiro.

Assim, constata-se que a modernização agrícola do front foi comandada pelo Estado e teve como apoio a população migrante do sul. Essa população, por sua vez, por meio do uso agrícola desse subespaço do território brasileiro, estruturou-se enquanto elite local e regional. O processo de redivisão político-administrativa do estado do Mato Grosso revela um dos mecanismos utilizados por essa elite para o acesso aos recursos e ao poder. 
SILVA, S.C. da. A criação de municípios no front e a formação da elite ...

\section{Considerações finais}

A nova ocupação do território matogrossense deu-se à custa da dizimação de grande parte da população original. Vários grupos indígenas e mesmo a população cabocla que migrou para lá em séculos anteriores foram subjugados à nova lógica de estruturação e uso do território, transformando o front em uma grande área de tensões sócio-espaciais.

A elite do agronegócio no Mato Grosso configura-se, então, em elemento condicionante na conformação do uso corporativo do território, que se concretiza na família de municípios do agronegócio. Ela explicita um poder local modificado porque é urbano e que agrega a racionalidade empresarial, tendo uma atuação agressiva no sentido de incorporar políticas públicas acordadas com o projeto da produção de commodities.

As atividades ligadas à vida de todas as pessoas, inclusive dos migrantes que chegam às regiões ditas prósperas, são também de responsabilidade do Estado, ou seja, são recursos que o Estado tem que garantir para atender a população com educação, saúde, habitação, transporte e toda assistência social. Os municípios, sendo a instância do Estado mais próxima do lugar da existência das pessoas, são os que têm que arcar com os investimentos nos setores que garantam a sobrevivência e manutenção dessas pessoas.

Entretanto, o poder público, ao garantir a modernização dos sistemas técnicos e normativos para uso das grandes empresas e da elite do agronegócio, fica desprovido de recursos para atender minimamente todo o "resto" do território, sobretudo das atividades ligadas à vida digna das pessoas. Com isso a desigualdade aprofunda-se e ganha a cara do novo período. A família de municípios do agronegócio é expressão do uso corporativo do território e do modo como o Estado torna-se um agente desse processo em suas diversas escalas.

Há uma relação profunda entre o processo de formação de fronteiras internas no Brasil, especialmente no front, e a modernização do território, que por sua vez conecta-se a processos 
SILVA, S.C. da. A criação de municípios no front e a formação da elite ...

mais abrangentes, como a difusão do modo de produção capitalista pelo mundo, sustentado pelos novos sistemas técnicos que colocam o mundo em interdependência.

A geração de novos municípios no front indica que a moderna agricultura necessita de um poder público correspondente a essa base produtiva. $\mathrm{O}$ surgimento de uma elite do agronegócio aponta a exigência por uma população ${ }^{4}$ "adequada" ao desenvolvimento dessas atividades econômicas. Essa combinação de variáveis leva à criação de um território especializado e vulnerável, uma vez que o dispêndio de recursos públicos é feito para atender a essa produção de comando externo.

A segregação sócio-espacial está estampada na paisagem da família de municípios do agronegócio. Em alguns municípios, encontra-se a presença de 'bairros de maranhenses' que possuem infra-estrutura bastante precária. Em outros municípios, produtores rurais nos informaram de ações da prefeitura em remover os migrantes do Norte e Nordeste, buscando 'devolvê-los', colocando-os em ônibus que realizavam o trajeto de volta, sendo, portanto, absolutamente negada sua permanência nesses municípios (ARRUZZO, 2005, p. 110).

Dessa maneira, encontra-se mais um atributo dos municípios do agronegócio, é a fissura sócio-espacial. Regra geral é a existência de uma elite do agronegócio originária do Sul do país, e o restante é a população local ou de migrantes nordestinos.

Pode-se dizer que a figura do "coronel" foi em parte substituída pela figura do empresário do agronegócio, mantendo alguns mecanismos da prática dos coronéis, absorvendo, entretanto, a racionalidade econômica e competitiva da moderna agricultura.

A elite local matogrossense é mais um elemento da família de municípios do agronegócio que indica um maior imbricamento do poder público Estatal com o mercado, e também o crescimento da importância das políticas das empresas.

\footnotetext{
${ }^{4}$ Ao invés do termo do mercado "mão-de-obra qualificada", preferimos usar o conceito de "população", tal como a definiu Raffestin (1993), quando a considera como um trunfo do poder.
} 
SILVA, S.C. da. A criação de municípios no front e a formação da elite ...

\section{Referências bibliográficas}

ALVES, Vicente Eudes Lemos. "A mobilidade sulista e a expansão da fronteira agrícola brasileira”. In: Agrária. São Paulo, $\mathrm{n}^{\mathrm{o}} 2$, 2005. pp. 40-68.

ARRUZZO, Roberta Carvalho. "Modernização Agrícola, trabalho e organização espacial na BR-163". BERNADES, Júlia Adão \& FREIRE FILHO, Osni de Luna. Geografias da soja: BR-163 fronteiras em mutação. Rio de Janeiro: Arquimedes Edições, 2005. pp.99-113.

BRUNHES, Jean. Geografia Humana. Rio de Janeiro: Editora Fundo de Cultura, 1962 [1956].

CASTRO, Iná Elias de. O mito da necessidade - discurso e prática do regionalismo nordestino. Rio de janeiro: Bertrand Brasil S.A., 1992.

CATAIA, Márcio. Território Nacional e Fronteiras Internas: a Fragmentação do Território Brasileiro. Tese de Doutorado, Departamento de Geografia, FFLCH-USP. Paulo, São Paulo, 2001. $250 \mathrm{p}$

DEFFONTAINES, Pierre. "Como se Constitui no Brasil a Rêde das Cidades". In: Boletim Geográfico, ano II, $\mathrm{n}^{\mathrm{o}}$ 14, Parte I (p. 141-148) e no 15, Parte II (p. 299-308), Rio de Janeiro, 1944.

GEIGER, Pedro Pichas. A Evolução da Rêde Urbana Brasileira. Rio de Janeiro: Centro Brasileiro de Pesquisas Educacionais, 1963.

HAESBAERT, Rogério. "A noção de rede regional: reflexões a partir da migração 'gaúcha' no Brasil”. In: Revista Território, ano III, nº 4, jan/jun de 1998.

KAHIL, Samira Peduti. "Usos do Território: uma questão política". In: Anais do X Encontro de geógrafos da América Latina. De 20 a 26 de março de 2005. pp. 7193-7204.

MILLS, C. Whight. A elite do poder. Rio de Janeiro: Zahar editores, 1981 [1956]). 
SILVA, S.C. da. A criação de municípios no front e a formação da elite ...

MORAES, Antonio Carlos Robert \& COSTA, Wanderley Messias da. Geografia crítica: a valorização do espaço. São Paulo: HUCITEC, 1987.

RAFFESTIN, Claude. Por uma geografia do Poder. São Paulo: Ática, 1993 [1980].

SANTOS, Milton. As Cidades nos Países Subdesenvolvidos. Rio de Janeiro: Civilização Brasileira, 1965.

SANTOS, Milton. "Sociedade e Espaço: A Formação Social Como Teoria e Como Método". In: Boletim Paulista de Geografia, ${ }^{\circ}$ 54. São Paulo: AGB, 1977. pp. 81-99

Hicitec, 1994.

.Por uma Economia Política da Cidade. São Paulo,

A Natureza do Espaço: Técnica e Tempo, Razão e Emoção. São Paulo: Edusp, 2002 [1996].

SANTOS, Milton \& SILVEIRA María Laura. O Brasil Território e Sociedade no Início do Século XXI. Rio de Janeiro: Record, 2001.

SILVA, Silvana Cristina da. A família de municípios do agronegócio: expressão da especialização produtiva no front agrícola. Dissertação de mestrado do Depto. de GeografiaUNICAMP, 2007.

SILVA, Silvana Cristina da \& CATAIA, Márcio. A Municipalização do Território: Algumas Considerações Sobre o Estado do Mato Grosso. In: VI Encontro Nacional da ANPEGE. Fortaleza de 28 a 30 de setembro de 2005.

SILVEIRA, María Laura. Um País, Uma Região: Fim de Século e Modernidades na Argentina. São Paulo: LABOPLAN-USP, 1999.

Recebido em abril de 2008 Aceito em março de 2009 
